HELICOBACTER PYLORI

\title{
Current concepts in the management of Helicobacter pylori infection: the Maastricht III Consensus Report
}

\author{
P Malfertheiner, F Megraud, C O'Morain, F Bazzoli, E El-Omar, D Graham, R Hunt, T Rokkas, N Vakil, \\ E J Kuipers, The European Helicobacter Study Group (EHSG)
}

Gut 2007;56:772-781. doi: 10.1136/gut.2006.101634

See end of article for authors' affiliations

\section{Correspondence to:} Professor P Malfertheiner, Otto-von-GuerickeUniversität Magdeburg, Medizinische Fakultät,

Zentrum für Innere Medizin Klinik für Gastroenterologie, Hepatologie und Infektiologie, Leipziger Straße 44, D-39120 Magdeburg, Germany; peter.malfertheiner@ medizin.uni-magdeburg.de

Accepted 21 November 2006 Published Online First 14 December 2006
Background: Guidelines on the management of Helicobacter pylori, which cover indications for management and treatment strategies, were produced in 2000.

Aims: To update the guidelines at the European Helicobacter Study Group (EHSG) Third Maastricht Consensus Conference, with emphasis on the potential of $\mathrm{H}$ pylori eradication for the prevention of gastric cancer.

Results: Eradication of $\mathrm{H}$ pylori infection is recommended in (a) patients with gastroduodenal diseases such as peptic ulcer disease and low grade gastric, mucosa associated lymphoid tissue (MALT) lymphoma; (b) patients with atrophic gastritis; (c) first degree relatives of patients with gastric cancer; (d) patients with unexplained iron deficiency anaemia; and (e) patients with chronic idiopathic thrombocytopenic purpura. Recurrent abdominal pain in children is not an indication for a "test and treat" strategy if other causes are excluded. Eradication of $H$ pylori infection (a) does not cause gastro-oesophageal reflux disease (GORD) or exacerbate GORD, and (b) may prevent peptic ulcer in patients who are naive users of non-steroidal antiinflammatory drugs (NSAIDs). H pylori eradication is less effective than proton pump inhibitor (PPI) treatment in preventing ulcer recurrence in long term NSAID users. In primary care a test and treat strategy using a noninvasive test is recommended in adult patients with persistent dyspepsia under the age of 45 . The urea breath test, stool antigen tests, and serological kits with a high accuracy are non-invasive tests which should be used for the diagnosis of $H$ pylori infection. Triple therapy using a PPI with clarithromycin and amoxicillin or metronidazole given twice daily remains the recommended first choice treatment. Bismuth-containing quadruple therapy, if available, is also a first choice treatment option. Rescue treatment should be based on antimicrobial susceptibility.

Conclusion: The global burden of gastric cancer is considerable but varies geographically. Eradication of $H$ pylori infection has the potential to reduce the risk of gastric cancer development.
$\mathrm{T}$ he European Helicobacter Study Group (EHSG), founded in 1987 to promote multidisciplinary research into the pathogenesis of Helicobacter pylori, has organised successful annual meetings and arranged task forces on paediatric issues and clinical trials. Consensus meetings have been convened on who to treat, and how and when to treat patients with $H$ pylori infection. The most active area of research is into the link between $H$ pylori and gastric cancer, a major public health issue. The Third Maastricht Consensus Conference was convened to update guidelines on the management of $H$ pylori infection. Fifty experts from 26 countries, including primary care physicians, were involved in formulating the consensus held in March 2005. The experts were chosen based on their expertise and contribution to the published literature.

\section{METHODOLOGY AND STRUCTURE OF CONFERENCE PROCESS}

Current guidelines from Japan, China, North America, and Europe were reviewed at an introductory plenary session.

Working groups examined the following three topics relating to $H$ pylori infection:

- Indications/contraindications for eradication, focusing on dyspepsia, non-steroidal anti-inflammatory drugs (NSAIDs) or aspirin use, gastro-oesophageal reflux disease (GORD); and extraintestinal manifestations of the infection.

- Diagnostic tests and treatment of infection.

- Prevention of gastric cancer and other complications.
The recommendations were debated and modified according to a standard template. The strength of recommendations and evidence to support them were graded (table 1). For some statements the grade of recommendation did not match the level of evidence because either studies focusing on the same topic reported conflicting results, or interpretation of the studies by the experts led to a different grade of recommendation than expected from the level of evidence.

The statements and recommendations were edited and finally agreed at the concluding plenary session. Consensus was considered to have been reached if $70 \%$ or more of the experts supported the recommendation. The recommendations/ statements resulting from this rigorous process are reported in this manuscript.

\section{INDICATIONS/CONTRAINDICATIONS FOR H PYLORI ERADICATION}

The indications for $H$ pylori eradication listed as a strong recommendation in Maastricht II-2000 guidelines (table 2) were reconfirmed at this update (table 3 ).

Abbreviations: BabA2, blood group antigen binding adhesin 2; CagA, cytotoxin associated gene A; EHSG, European Helicobacter Study Group; GORD, gastro-oesophageal reflux disease; IDA, iron deficiency anaemia; ITP, idiopathic thrombocytopenic purpura; MALT, mucosa associated lymphoid tissue; NSAIDs, non-steroidal anti-inflammatory drugs; OipA, outer inflammatory protein A; PPIs, proton pump inhibitors; $\mathrm{RCT}$, randomised controlled trial; SabA, sialic acid binding adhesion; $\mathrm{UBT},{ }^{13} \mathrm{C}$-urea breath test; VacA, vacuolating associated gene $\mathrm{A}$ 
Table 1 Grades of scientific evidence supporting the recommendations formulated in the Maastricht III Consensus Report

\begin{tabular}{|c|c|c|c|}
\hline $\begin{array}{l}\text { Grade of } \\
\text { recommendation }\end{array}$ & $\begin{array}{l}\text { Evidence } \\
\text { level }\end{array}$ & & Type of studies \\
\hline A & 1 & $\begin{array}{l}\text { la } \\
1 b \\
1 c\end{array}$ & $\begin{array}{l}\text { Systematic review of randomised controlled trials (RCT) of good methodological } \\
\text { quality and with homogeneity } \\
\text { Individual RCT with narrow confidence interval } \\
\text { Non-controlled studies }\end{array}$ \\
\hline B & 3 & $\begin{array}{l}2 a \\
2 b \\
2 c \\
3 a \\
3 b\end{array}$ & $\begin{array}{l}\text { Systematic review of cohort studies (with homogeneity) } \\
\text { Individual cohort studies (including low quality RCT, eg }<80 \% \text { follow-up) } \\
\text { Non-controlled cohort studies/ecological studies } \\
\text { Systematic review of case-control studies (with homogeneity) } \\
\text { Individual case-control studies }\end{array}$ \\
\hline C & 4 & & Case series/poor quality cohort or case-control studies \\
\hline D & 5 & & $\begin{array}{l}\text { Expert opinion without explicit critical appraisal or based on physiology, bench } \\
\text { research or "first principles" }\end{array}$ \\
\hline
\end{tabular}

\section{$H$ pylori and MALT lymphoma}

Subsequent to Maastricht II, important new data have been published which have strengthened the indication for $H$ pylori eradication therapy in gastric MALT lymphoma.

Sixty two per cent of patients with low grade gastric MALT lymphoma have complete remission after $H$ pylori eradication within 12 months. $^{23}$

Predictors of response to eradication therapy in patients with low grade gastric MALT lymphoma are: $H$ pylori positivity; Lugano classification stage I; lymphoma confined to the stomach; gastric wall invasion confined to mucosa/submucosa; and the absence of gene $\mathrm{t}(11,18)(\mathrm{q} 21 ; \mathrm{q} 21)$, translocation with fusion of API2 and MALT1. Fusion of both leads to suppression of apoptosis and strongly predicts failure to respond to eradication therapy.

The Maastricht III-2005 consensus report concluded that $H$ pylori eradication is the treatment of first choice for $H$ pylori infected patients with stage I low grade gastric MALT lymphoma.

\section{$H$ pylori and dyspepsia}

A "test and treat" strategy is recommended in adult patients under the age of 45 years presenting with persistent dyspepsia (the age cut off point may vary between countries, depending on the prevalence of gastric cancer). A test and treat strategy has been validated by a primary care study on uninvestigated dyspepsia in Canada. ${ }^{4}$

$H$ pylori eradication gives modest, but significant benefit in non-ulcer dyspepsia. ${ }^{5}$ Economic modelling suggests that this benefit is cost effective. ${ }^{6}$ Twelve to 15 infected patients need to be treated to cure one patient with non-ulcer dyspepsia. ${ }^{6}$ This compares favourably with any other treatment available for non-ulcer dyspepsia. The eradication of $H$ pylori infection is

\section{Box 1: Recommendations}

1. $H$ pylori eradication is appropriate for patients infected with $\mathrm{H}$ pylori and investigated non-ulcer dyspepsia.

2. $H$ pylori test and treat is appropriate for patients with uninvestigated dyspepsia.

3. The effectiveness of $H$ pylori test and treat is low in populations with a low $H$ pylori prevalence and in this situation empirical acid suppression is an equivalent option. carried out once and leads to long term symptom improvement; it also reduces the risk of developing peptic ulcer disease, atrophic gastritis, and gastric cancer.

In areas of low $H$ pylori prevalence ${ }^{7}(<20 \%)$ proton pump inhibitor (PPI) empirical treatment or a test and treat strategy were considered to be equivalent options (box l).

\section{$H$ pylori and GORD}

The prevalence of $H$ pylori in patients with GORD is lower than in those without reflux disease. ${ }^{8}$ Most countries with a high prevalence of $H$ pylori also have a low prevalence of GORD. The falling prevalence of $H$ pylori infection and related diseases, including peptic ulcer disease and gastric cancer, in developed countries has been paralleled by an increase in GORD and its complications. The nature of this negative association is unclear. ${ }^{9} 10$

In an American study on $H$ pylori infection and, in particular, infection with CagA positive strains, the prevalence of $\mathrm{H}$ pylori infection was reported to be lower in patients with Barrett's oesophagus and adenocarcinoma of the cardia. ${ }^{11}$ This association has been confirmed in most but not all studies. ${ }^{12}{ }^{13}$ Severe inflammation involving the fundus of the stomach is associated with reduced gastric acid secretion and is inversely correlated with GORD and its complications.

\section{Box 2: Recommendations}

There is a negative association between the prevalence of $H$ pylori and GORD, but the nature of this relationship is uncertain.

1. H pylori eradication does not affect the outcome of PPI treatment in patients with GORD in Western populations.

2. Routine testing for $H$ pylori is not recommended in GORD.

3. $H$ pylori testing should be considered in patients receiving long term maintenance treatment with PPIs.

Profound acid suppression affects the pattern and distribution of gastritis favouring corpus dominant gastritis. It may accelerate the process of loss of specialised glands, leading to atrophic gastritis.

$H$ pylori eradication halts the progression of atrophic gastritis and may lead to regression of atrophy. The effect on intestinal metaplasia is uncertain. 
Table 2 Strong recommendations for $\mathrm{H}$ pylori eradication already considered in the Maastricht II-2000 Consensus Report.

\begin{tabular}{lll}
\hline Recommendation (H pylori positive) & $\begin{array}{l}\text { Level of scientific } \\
\text { evidence }\end{array}$ & $\begin{array}{l}\text { Grade of } \\
\text { recommendation }\end{array}$ \\
\hline DU/GU (active or not, including complicated PUD) & $1 \mathrm{a}$ \\
MALToma & $1 \mathrm{c}$ & $\mathrm{A}$ \\
Atrophic gastritis & $2 \mathrm{a}$ & $\mathrm{B}$ \\
After gastric cancer resection & $3 \mathrm{~b}$ & $\mathrm{~B}$ \\
Patients who are first degree relatives of patients with gastric cancer & $3 \mathrm{~b}$ & $\mathrm{~B}$ \\
Patients wishes (after full consultation with their physician) & 5 & $\mathrm{~A}$ \\
\hline
\end{tabular}

DU, duodenal ulcer; GU, gastric ulcer; PUD, peptic ulcer disease; MALToma, mucosa associated lymphoid tissue lymphoma.

Eradication of $H$ pylori does not cause GORD, ${ }^{14-16}$ and does not exacerbate symptoms in patients with GORD either when untreated ${ }^{17}$ or in those receiving PPI maintenance treatment. ${ }^{18}$

Screening for $H$ pylori in patients with GORD needs more formal study, including a cost effectiveness analysis, and is currently not recommended.

\section{$H$ pylori and PPIs}

Profound acid suppression affects the pattern and distribution of gastritis, favouring corpus dominant gastritis. ${ }^{19}$ Profound acid suppression with PPIs or high dose histamine 2 receptor antagonists in the presence of $H$ pylori positive corpus gastritis may accelerate the loss of specialised glands, leading to atrophic gastritis and, potentially, gastric cancer. In patients with reflux oesophagitis receiving long term acid suppression, eradication of $H$ pylori infection decreases inflammation and gastritis activity, and reverses corpus gastritis (box 2). ${ }^{18}$

\section{$H$ pylori and NSAIDs}

The relationship between $H$ pylori infection and NSAIDs in gastroduodenal pathology is complex: $H$ pylori and NSAIDs independently and significantly increase the risk of peptic ulcer bleeding by 1.79- and 4.86-fold, respectively. The risk of ulcer bleeding is increased by 6.13 -fold when both factors are present. $^{20}$

Results of $H$ pylori eradication in NSAIDs users are conflicting. Part of the problem is that both NSAIDs and $H$ pylori can cause peptic ulcers. $H$ pylori eradication can only be expected to prevent recurrence of $H$ pylori ulcers and while it may also reduce the incidence of ulcers among those with both $H$ pylori and NSAID use, the effect will vary depending on the proportion with true $H$ pylori ulcers in the population studied. In chronic NSAID users with peptic ulcer, $H$ pylori eradication was no better than placebo for maintaining a remission of peptic ulcer with PPI treatment at six months. ${ }^{21}$ PPI maintenance treatment is better than $H$ pylori eradication alone in preventing upper gastrointestinal bleeding. ${ }^{22}$ In contrast, in patients with $H$ pylori infection who are naive NSAID users, $H$ pylori eradication is better than placebo in preventing peptic ulcer and upper gastrointestinal bleeding at six months. ${ }^{23}{ }^{24}$

Patients who are receiving long term aspirin and have ulcer disease and a history of significant bleeding should be tested for $H$ pylori infection and, if positive, be given eradication therapy. ${ }^{22} 25$ Patients receiving long term PPI treatment for prevention of NSAID ulcers should be tested for $H$ pylori to reduce the PPI-H pylori interaction leading to accelerated loss of specialised glands and atrophic gastritis (box 3).

Table 3 Recommendations for $\mathrm{H}$ pylori eradication formulated in the Maastricht III Consensus Report, with levels of scientific evidence and grades of recommendation

\begin{tabular}{|c|c|c|}
\hline Recommendations & Level of evidence & Grade of recommendation \\
\hline $\begin{array}{l}\text { H pylori eradication is an appropriate option for patients infected with } H \text { pylori and investigated non-ulcer } \\
\text { dyspepsia }\end{array}$ & la & A \\
\hline$H$ pylori test and treat is an appropriate option for patients with uninvestigated dyspepsia & la & A \\
\hline $\begin{array}{l}\text { Effectiveness of } \mathrm{H} \text { pylori test and treat is low in populations with a low } \mathrm{H} \text { pylori prevalence. In this situation } \\
\text { the test and treat strategy or empirical acid suppression is an appropriate option }\end{array}$ & $2 a$ & B \\
\hline$H$ pylori eradication does not cause GORD & $1 b$ & A \\
\hline & & \\
\hline $\begin{array}{l}\text { populations } \\
\text { Routine testing for } H \text { pylori is not recommended in GORD }\end{array}$ & 16 & A \\
\hline & $\begin{array}{l}1 b \\
2 b\end{array}$ & $\begin{array}{l}\text { A } \\
B\end{array}$ \\
\hline $\begin{array}{l}\text { There is a negative association between the prevalence of } H \text { pylori and GORD in Asia, but the nature of this } \\
\text { relationship is uncertain }\end{array}$ & $2 b$ & B \\
\hline $\begin{array}{l}\text { In patients receiving long term NSAIDs and who have peptic ulcer and/or ulcer bleeding, PPI maintenance } \\
\text { treatment is better than } \mathrm{H} \text { pylori eradication in preventing ulcer recurrence and/or bleeding }\end{array}$ & 16 & A \\
\hline $\begin{array}{l}\text { H pylori eradication is of value in chronic NSAID users but is insufficient to prevent NSAID related ulcer } \\
\text { disease completely }\end{array}$ & 16 & A \\
\hline In naïve users of NSAIDs, $H$ pylori eradication may prevent peptic ulcer and or bleeding & $1 \mathrm{~b}$ & A \\
\hline
\end{tabular}




\section{Box 3: Recommendations}

$H$ pylori eradication is of value in chronic NSAID users but is insufficient to prevent NSAID related ulcer disease completely.

1. In naïve NSAID users $H$ pylori eradication may prevent peptic ulcer and bleeding.

2. In patients receiving long term NSAIDs and with peptic ulcer and/or ulcer bleeding, PPI maintenance treatment is better than $H$ pylori eradication in preventing ulcer recurrence and/or bleeding.

3. Patients who are receiving long term aspirin who bleed should be tested for $H$ pylori and, if positive, receive eradication therapy.

\section{Extraintestinal disease}

Some studies suggest that $H$ pylori infection may cause iron deficiency anaemia (IDA) and idiopathic thrombocytopenic purpura (ITP). Possible pathogenetic mechanisms involved in IDA in patients with $H$ pylori infection include: occult blood loss secondary to chronic erosive gastritis; decreased iron absorption secondary to chronic gastritis of the corpus causing hypo- or achlorhydria; increased iron uptake and use by bacteria. ${ }^{26} \mathrm{H}$ pylori eradication reverses IDA in patients with asymptomatic gastritis $^{27}$ and improves oral iron absorption..$^{28}$

Some studies suggest that there is a higher prevalence of $H$ pylori infection in patients with ITP than in controls. ${ }^{29}$ Moreover, a review of published data on $H$ pylori infection and ITP confirmed that eradication therapy induces a significant positive platelet response in a proportion of patients with ITP. ${ }^{30-33}$ It was recommended that $H$ pylori infection should be sought for and treated in patients with unexplained IDA and in those with ITP. $H$ pylori infection has no proven role in other extraintestinal diseases (box 4).

\section{$\boldsymbol{H}$ pylori infection in children}

Recurrent abdominal pain is not an indication for a test and treat strategy for $\mathrm{H}$ pylori infection in children. The primary goal of a diagnostic investigation in recurrent abdominal pain should be to determine the cause of the presenting gastrointestinal symptoms, and not the presence of $H$ pylori infection.

However, children with upper gastrointestinal symptoms should be tested for $H$ pylori infection (after exclusion of other causes of the symptoms) and should be treated if they have the infection.

In children and adolescents, IDA refractory to iron supplementation is an indication to test for $H$ pylori infection and for eradication therapy if positive. This should be carried out after exclusion of other causes, such as coeliac disease and inflammatory bowel disease.

No other substantial aspects have been brought forward in respect of the previously published guidelines. ${ }^{34} 35$

\section{Box 4: Recommendations}

$H$ pylori infection should be sought for and treated in patients with:

1. Unexplained iron deficiency anemia.

2. Idiopathic thrombocytopenic purpura.

$H$ pylori has no proven role in other extraintestinal diseases.

\section{Box 5: Recommendations}

Serology should be considered as a diagnostic test when others could be false negative, such as in patients with:

1. Bleeding ulcers, gastric atrophy, MALT lymphoma.

2. Recent or current use of PPls and antibiotics.

\section{DIAGNOSTIC PROCEDURES}

Non-invasive tests for the diagnosis of $H$ pylori infection include: the ${ }^{13} \mathrm{C}$-urea breath test (UBT); stool antigen tests (polyclonal antibody, monoclonal antibody, and office based); and immunological tests (laboratory and office based tests and tests on saliva and urine) (table 4).

The diagnostic accuracy of the UBT is $>95 \%$ in studies. The UBT is an accurate, practical, and readily available test. ${ }^{36}$

The stool antigen test is appropriate when multiple specimens are tested as a batch. However, it is necessary to store stool samples at $-20^{\circ} \mathrm{C}$ before testing. The sensitivity of the stool antigen test decreased to $69 \%$ after 2-3 days at room temperature. In a systematic review of 89 studies evaluating the stool antigen test the sensitivity and specificity were $91 \%$ and $93 \%$, respectively. ${ }^{37}$

Serology is a widely available and inexpensive non-invasive test, but the diagnostic accuracy is low $(80-84 \%) .^{38}$ Tests that detect active infection, although more expensive, are preferable to serology as these reduce the number of patients inappropriately treated for presumed $H$ pylori infection. ${ }^{39}{ }^{40}$ Some kits for serology with a high accuracy $(>90 \%)$ are recommended in validated settings

\section{Special role of serology}

PPI treatment can result in false negative invasive and noninvasive diagnostic tests. PPI should be stopped for at least two weeks before testing. However, this does not apply to serology. ${ }^{41-46}$ A positive serological test with negative histology and UBT suggests the presence of an unrecognised $H$ pylori infection, and additional investigations to confirm whether the serological test is false positive or reflects active infection should be carried out. False positive non-invasive tests are more common in low prevalence populations, requiring additional confirmation before treatment. ${ }^{47} 48$

Serological tests are recommended to assess $H$ pylori in patients with a bleeding ulcer and conditions associated with a low bacterial density (extensive mucosal atrophy ${ }^{45}$ and MALT lymphoma) ${ }^{46}$ (box 5). The rapid urease test, culture, and histology as well as UBT have shown a limited sensitivity in patients presenting with acute bleeding peptic ulcer. Polyclonal stool antigen tests have a low specificity owing to cross reactivity with blood products. Serological tests, and in particular detection of antibodies against the specific antigen CagA, which is immunogenic and long lasting, are also the best method to document the link of gastric cancer with $\mathrm{H}$ pylori infection. ${ }^{49}$

Office based serological tests or near patient tests are extremely convenient, but they are not accurate and are currently not recommended ${ }^{50}$ (box 6).

\section{Box 6: Recommendations}

1. Serology based office tests have no current role in the management of $H$ pylori infection.

2. The detection of specific $H$ pylori antibodies in urine and saliva has no current role in patient management but can be helpful for epidemiological studies. 


\section{Box 7: Recommendation}

The detection of $H$ pylori pathogenic factors and the study of host genetic polymorphisms is currently not recommended in the management of $\mathrm{H}$ pylori infection.

Kits are available to diagnose $H$ pylori antibodies in urine and saliva. Their main advantage is their non-invasiveness and convenience. Unfortunately, their sensitivity is low. Therefore they are not useful in patient management but can be useful in epidemiological studies.

\section{Detection of pathogenic factors}

Some strains of $H$ pylori are more virulent than others. ${ }^{51}$ Important pathogenic factors are CagA, a product of a gene of the cag pathogenicity island; VacA, a cytotoxin produced in various amounts; and $\mathrm{BabA}_{2}$, an adhesin which recognises the blood group antigen $\mathrm{A}$ and allows $H$ pylori to adhere to gastric epithelial cells. Other factors, for example, OipA and SabA, may also determine disease. Furthermore, host genetic factors may determine disease outcome ${ }^{52}$ The association with $H$ pylori pathogenic factors and host genetic factors is real in Western populations, but the limited strength of the association does not allow a reliable prediction of the outcome at an individual level. Moreover, the tests are cumbersome and expensive and of little relevance in the management of $H$ pylori infection (box 7).

\section{Role for urease test}

The rapid urease test can detect the presence of $H$ pylori, within one hour with a satisfactory accuracy $(>90 \%) .{ }^{53}$ False negative results can occur in patients taking antisecretory drugs. It is

\section{Box 8: Recommendation}

A positive rapid urease test is sufficient to initiate treatment.

\section{Box 9: Recommendations}

$H$ pylori eradication should be confirmed at least four weeks after treatment.

1. A UBT is recommended if available.

2. If not available, a laboratory based stool test, preferably using monoclonal antibodies, could be used.

acceptable to initiate eradication therapy on the basis of a positive rapid urease test (box 8 ).

\section{Follow-up after treatment}

Non-invasive tests should be employed for confirmation of eradication except in cases where repeat endoscopy is indicated, for example in patients with gastric ulcer. Systematic reviews of the studies performed in this context indicate that UBT is the best option, with a sensitivity of $94 \%$ and a specificity of $95 \%{ }^{36}{ }^{54}$ The accuracy of the stool antigen tests is less than that of the UBT. ${ }^{55-58}$ However, when a UBT is not available, a stool test can be used. There are a number of stool tests available (one using monoclonal antibodies, laboratory and office based and the other polyclonal antibodies). The sensitivity of the test is lower if polyclonal antibodies ${ }^{59}$ or an office test is used. Confirmation of $H$ pylori eradication should be performed at least four weeks after treatment (box 9).

Table 4 Recommendations for diagnosis of $\mathrm{H}$ pylori formulated in the Maastricht III Consensus Report, with levels of scientific evidence and grades of recommendation

\begin{tabular}{|c|c|c|}
\hline Recommendations & Level of evidence & Grade of recommendation \\
\hline $\begin{array}{l}\text { The non-invasive tests that can be used for the test and treat strategy are UBT and the stool antigen tests. } \\
\text { Certain kits for serology with high accuracy can also be applied }\end{array}$ & la & B \\
\hline $\begin{array}{l}\mathrm{PPI} \text { is a source of false negative diagnostic tests except serology. PPIs should be stopped for at least } 2 \text { weeks } \\
\text { before performing a diagnostic test }\end{array}$ & 16 & A \\
\hline $\begin{array}{l}\text { Serology should be considered as a diagnostic test when other diagnostic tests might be false negative, such } \\
\text { as in patients with bleeding ulcers, gastric atrophy, MALT lymphoma, and recent or current use of PPIs and } \\
\text { antibiotics }\end{array}$ & 2 & B \\
\hline The serological tests are not all equivalent and different tests may be applied in different situations & $2 b$ & B \\
\hline $\begin{array}{l}\text { The detection of specific } \mathrm{H} \text { pylori antibodies in urine and saliva has no current role in patient management } \\
\text { but can he helpful for epidemiological studies }\end{array}$ & 16 & A \\
\hline Serology based near doctor-patient tests have no current role in the management of $H$ pylori infection & 1 & A \\
\hline $\begin{array}{l}\text { Detection of } H \text { pylori pathogenic factors and the study of host genetic polymorphisms is not helpful in the } \\
\text { management of } H \text { pylori infection }\end{array}$ & $3 b$ & D \\
\hline $\begin{array}{l}\text { It is recommended that a follow-up evaluation to confirm successful eradication be performed after } \mathrm{H} \text { pylori } \\
\text { eradication with UBT if available. If not available a laboratory based stool test, preferably using monoclonal } \\
\text { antibodies, could be used }\end{array}$ & 16 & A \\
\hline $\begin{array}{l}\text { Culture and antimicrobial sensitivity testing should be routinely performed: } \\
\text { Before clarithromycin based treatment, if primary resistance to clarithromycin is greater than } 15-20 \% \text { in the } \\
\text { respective area }\end{array}$ & & \\
\hline $\begin{array}{l}\text { After two treatment failures with different antibiotics } \\
\text { Monitoring of primary antibiotic resistance should be carried out in reference laboratories in different } \\
\text { areas: }\end{array}$ & 16 & B \\
\hline $\begin{array}{l}\text { In patients presenting for endoscopy without pretreatment, a positive rapid urease test is sufficient to initiate } \\
\text { treatment }\end{array}$ & 2 & A \\
\hline
\end{tabular}




\section{Box 10: Recommendations}

1. The threshold of clarithromycin resistance at which this antibiotic should not be used, or clarithromycin susceptibility testing performed, is $15-20 \%$.

2. Testing metronidazole susceptibility is not routinely necessary.

3. Metronidazole susceptibility testing needs further standardisation.

\section{TREATMENT OF H PYLORI INFECTION}

Numerous clinical trials have been published since the last Maastricht conference. Table 5 shows the recommendations for treatment of $H$ pylori infection formulated at the Maastricht III Consensus Conference. Standard triple therapy composed of PPI, clarithromycin and amoxicillin/or metronidazole is more successful if extended to more than seven days. Increased resistance to antibiotics used in the PPI triple therapy needs to be considered in the selection of treatment. Recently, sequential treatment consisting of five days of a PPI plus amoxicillin followed by five additional days of a PPI plus clarithromycin plus tinidazole has been shown to be better than the combination of a PPI plus amoxicillin and clarithromycin for seven days ${ }^{60}{ }^{61}$ and deserves further evaluation in different regions.

\section{Antimicrobial resistance}

The mechanism of resistance of $H$ pylori strains to clarithromycin is well understood. Its methods of detection are reliable and its clinical relevance has been proved.

The prevalence of clarithromycin resistance in Europe was measured in a European study in 1997-98 and was, overall, $10 \%$, with important differences between northern $(4 \%)$ and southern European countries (18.5\%). ${ }^{62}$ There was a correlation between the prevalence of $H$ pylori clarithromycin resistance and the consumption of macrolides in the corresponding regions expressed as the daily dose per 1000 inhabitants in $1997 . .^{63}$

Clarithromycin resistance is increasing. It is the main risk factor for treatment failure. ${ }^{64-66}$ Treatment should achieve an eradication rate of $\geqslant 80 \% .{ }^{67}$ The threshold of clarithromycin resistance at which this antibiotic should not be used, or a clarithromycin susceptibility test should be performed, is 15$20 \%$.

\section{Box 11: Recommendations}

1. For PPI (standard dose bid), clarithromycin (500 mg bid), amoxicillin (1000 mg bid) or metronidazole (400 or 500 $\mathrm{mg}$ bid), 14 day treatment is more effective than seven days (by $12 \%$ (95\% confidence interval $7 \%$ to $17 \%$ ). A seven day treatment may be acceptable where local studies show that it is effective.

2. PPI-clarithromycin-amoxicillin or metronidazole treatment is the recommended first choice treatment in populations with less than 15-20\% clarithromycin resistance. In populations with less than $40 \%$ metronidazole resistance PPI-clarithromycin-metronidazole is preferable. Quadruple treatments are alternative first choice treatments.

3. The same first choice $H$ pylori treatments are recommended world wide, although different doses may be appropriate.

\section{Box 12: Recommendations}

1. Bismuth-containing quadruple treatments remain the best second choice treatment, if available.

2. PPI-amoxicillin or tetracycline and metronidazole are recommended if bismuth is not available.

In vitro resistance to metronidazole may not accurately reflect in vivo resistance. ${ }^{68}$ For this reason metronidazole testing is not recommended routinely in clinical practice (box 10).

In susceptible strains the combination of PPI-clarithromycinmetronidazole is more successful than the combination of PPIclarithromycin-amoxicillin ( $97 \% \vee 88 \%$, respectively). In the case of clarithromycin resistance alone, the eradication rates are also higher with PPI-clarithromycin-metronidazole than with PPI-clarithromycin-amoxicillin (50\% $v 18 \%$, respectively). In cases of metronidazole resistance when a PPI-clarithromycinmetronidazole regimen is used, there is a $25 \%$ decrease in eradication rate $(72 \% v 97 \%){ }^{69}$

Based on these data, the predicted eradication rates for the PPI-clarithromycin-metronidazole combination show a better efficacy than PPI-clarithromycin-amoxicillin, which is nullified only when metronidazole resistance reaches $40 \%{ }^{70}$

A 14 day treatment led to a $12 \%$ (95\% confidence interval 7 to $17 \%$ ) higher eradication rate based on a single meta-analysis. ${ }^{71}$ Few studies have compared the cost effectiveness of these different strategies. ${ }^{72}$ Numerous studies with PPI triple therapy for seven days, mainly from European countries, confirm that this is still a valid duration for this treatment. ${ }^{70}$

Bismuth-containing quadruple therapy ( 10 or 14 days) is an option for the first line treatment. It leads to satisfactory eradication rates despite the increased resistance to both clarithromycin and metronidazole.

First choice treatment in various geographical regions world wide was also examined and finally, a global statement including the different points mentioned above was voted upon (box 11).

\section{Second choice treatment}

Bismuth based quadruple therapy is a preferred option as second choice treatment if not previously used. However, the participants highlighted the fact that bismuth is not currently available in many countries.

PPI triple treatments have been tested as second choice treatment. Clarithromycin should not be used unless phenotypic or genotypic tests show that the strain is susceptible. The eradication rate obtained with the combination PPI-amoxicillin-metronidazole was $89 \%$ and $64 \%$ for metronidazole susceptible and resistant strains, respectively. In a clinical trial using this combination as a second choice treatment, the global eradication rate was $64 \% .^{73}$ Another combination, for which limited data exist, is PPI-tetracycline-metronidazole with an eradication of $91 \%$ (box 12 ). ${ }^{74}$

\section{Third choice treatment}

Two other classes of antibiotics have emerged in the treatment of $H$ pylori infection: a fluoroquinolone, levofloxacin; and a rifamycin, rifabutin.

\section{Box 13: Recommendation}

Rescue treatment should be based on antimicrobial susceptibility testing. 
Table 5 Recommendations for treatment of $H$ pylori infection formulated in the Maastricht III Consensus Report, with levels of scientific evidence and grades of recommendation

\begin{tabular}{|c|c|c|}
\hline Recommendations & Level of evidence & Grade of recommendation \\
\hline $\begin{array}{l}\text { The threshold of clarithromycin resistance at which empirical use of this antibiotic should be abandoned, or } \\
\text { pretreatment clarithromycin susceptibility testing performed, is } 15-20 \%\end{array}$ & la & A \\
\hline $\begin{array}{l}\text { Testing for metronidazole susceptibility is not routinely necessary in the management of } \mathrm{H} \text { pylori infection. } \\
\text { Metronidazole susceptibility testing needs further standardisation before it can be recommended }\end{array}$ & $1 a-c$ & A \\
\hline $\begin{array}{l}\text { There is a small advantage in using a PPI-clarithromycin-metronidazole combination instead of PPI- } \\
\text { clarithromycin-amoxicillin as the first choice treatment }\end{array}$ & la & A \\
\hline $\begin{array}{l}\text { PPI-clarithromycin-amoxicillin or metronidazole treatment remains the recommended first choice } \\
\text { treatment in populations with less than } 15-20 \% \text { clarithromycin resistance prevalence. In populations } \\
\text { with less than } 40 \% \text { metronidazole resistance prevalence PPI-clarithromycin-metronidazole is preferable } \\
\text { Quadruple therapies are alternative first choice treatments }\end{array}$ & & \\
\hline $\begin{array}{l}\text { The same first choice } H \text { pylori treatments are recommended world wide, although different doses may be } \\
\text { appropriate }\end{array}$ & $1 b$ & A \\
\hline $\begin{array}{l}\text { - Bismuth-based quadruple therapies remain the best second choice treatment, if available. If not, a PPI, } \\
\text { amoxicillin or tetracycline and metronidazole are recommended }\end{array}$ & & \\
\hline The rescue treatment should be based on antimicrobial susceptibility testing & $2 c$ & B \\
\hline
\end{tabular}

These antibiotics have been evaluated for the most part in first choice treatments with PPI and amoxicillin rather than rescue treatments, with a good success rate.

However, rifabutin is an antibiotic which can select resistance among Mycobacteria, so it must be used cautiously. $H$ pylori resistance to rifabutin may occur but is rare.

Many studies have included levofloxacin and obtained good eradication rates. ${ }^{75}{ }^{76}$ Unfortunately, none of them tested for fluoroquinolone susceptibility. One can assume that the strains were susceptible. Recent data showed that levofloxacin resistance reached $20 \%$ in some areas and can result in eradication failure.

Owing to the variety of clinical situations and antibiotics available in different countries, no specific recommendation was given for third choice treatment except to perform susceptibility testing.

Culture for the management of $H$ pylori infection has been neglected for a long time, despite the fact that several studies have shown that higher eradication rates are obtained when antibiotics are chosen based on susceptibility testing rather

Table 6 Statements concerning the relation between $\mathrm{H}$ pylori and gastric cancer formulated in the Maastricht III Consensus Report, with levels of scientific evidence and grades of recommendation

\begin{tabular}{|c|c|c|}
\hline Statements & Level of evidence & Grade of recommendation \\
\hline The global burden of gastric cancer increasing, predominantly in developing countries & ${ }^{*} 1$ & A \\
\hline$H$ pylori infection is the most common proven risk factor for human non-cardiac gastric cancer & & A \\
\hline The risk for gastric cancer development depends on bacterial virulence factors & & A \\
\hline The risk for gastric cancer development depends on host genetic factors & & B \\
\hline Environmental factors contribute to the risk of gastric cancer & & A \\
\hline $\begin{array}{l}\text { Evidence for } \mathrm{H} \text { pylori as an important factor for gastric cancer development is shown by experimental } \\
\text { animal models }\end{array}$ & & B \\
\hline Eradication of $H$ pylori prevents development of pre-neoplastic changes of the gastric mucosa & 16 & A \\
\hline Eradication of $\mathrm{H}$ pylori has the potential to reduce the risk of gastric cancer development & 1c & B \\
\hline $\begin{array}{l}\text { The optimal time to eradicate } \mathrm{H} \text { pylori is before pre-neoplastic conditions (atrophy, intestinal } \\
\text { metaplasia) are present, probably in early adulthood }\end{array}$ & 16 & A \\
\hline $\begin{array}{l}\text { H pylori eradication for gastric cancer prevention is cost effective in economic analyses. Feasibility } \\
\text { studies are required to evaluate further the benefits and risks of this strategy }\end{array}$ & *2 & B \\
\hline The potential for gastric cancer prevention on a global scale is restricted by currently available treatments & 16 & A \\
\hline New treatments are required for a global strategy of eradication to prevent gastric cancer & & A \\
\hline H pylori eradication for gastric cancer prevention in populations at risk should he evaluated and considered & $2 a$ & B \\
\hline
\end{tabular}

${ }^{*} 1$ grade of recommendation differs for some statements from the criteria presented in table 1, because the expert group interpreted the study results in a different way or more studies on the same topic had conflicting results; *2 cost analysis studies currently available are based on different economic models and scenarios. 
than chosen empirically. ${ }^{73} 7778$ This may be a cost effective approach. ${ }^{79}$ The high impact of clarithromycin resistance led to the proposal to perform culture and antimicrobial susceptibility testing when the resistance rate reaches $15-20 \%$. Culture and sensitivity may help in decision making after the failure of a second choice treatment. We recommend that monitoring of primary antibiotic resistance be carried out in different regions in order to appreciate the risk of failure linked to antimicrobial resistance (box 13).

\section{PREVENTION OF GASTRIC CANCER}

Gastric cancer is a major public health issue and the global burden of gastric cancer is increasing, particularly in developing countries (table 6). H pylori infection is the major cause of chronic gastritis, a condition that initiates the pathogenic sequence of events leading to atrophic gastritis, metaplasia, dysplasia and subsequently, cancer. Pooled analyses of prospective seroepidemiological studies have shown that people with $H$ pylori infection are at a statistically significantly increased risk of developing non-cardiac gastric cancer. ${ }^{80}$ It is also well established that both the intestinal and diffuse histological types of gastric cancer are significantly associated with the $H$ pylori infection. Non-randomised clinical follow-up studies in Japan have shown that gastric cancer rates are significantly higher in patients with $H$ pylori infection than in those in whom the infection was eradicated.$^{81}$ Metachronous tumour rates are also higher in those with persisting infection than in those without, after endoscopic resection for early gastric cancer. ${ }^{82}$

Furthermore, follow-up studies in Sweden and Denmark of patient cohorts undergoing hip replacement procedures show statistically significantly lower rates of gastric cancer. This may be explained by the possibility that high doses of prophylactic antibiotics incidentally eradicate $H$ pylori infection. ${ }^{83}$ Thus, it was agreed that $H$ pylori infection is the most common proven risk factor for human non-cardiac gastric cancer.

Infection with cagA positive strains of $H$ pylori increases the risk for gastric cancer over the risk associated with $H$ pylori infection alone. Determining the cagA status in $H$ pylori infection may confer additional benefit in identifying populations at greater risk for gastric cancer. ${ }^{84}$ Interleukin 1 gene cluster polymorphisms are associated with a higher risk of hypochlorhydria (odds ratio $=9.1$ ) and of gastric cancer (odds ratio $=1.9) .{ }^{52}$ Potential extrinsic and intrinsic factors in gastric carcinogenesis include: hereditary/family history, both direct and indirect (social inheritance); autoimmune (H pylori may trigger the onset of autoimmune atrophic gastritis in some patients with pernicious anaemia in diabetes type I, autoimmune chronic gastritis is common and rarely associated with $H$ pylori infection); environmental (occupational exposure/ nitrate/nitrite/nitroso compounds); nutritional (salt, pickled food, red meat, smoking); general (low socioeconomic status, geography); pharmacological (gastric acid inhibition). ${ }^{85-90}$ All these lines of evidence suggest that bacterial virulence factors, host genetic factors, and environmental factors contribute to the risk of developing gastric cancer. ${ }^{91}$

$H$ pylori eradication prevents development of pre-neoplastic changes (atrophic gastritis and intestinal metaplasia) of the gastric mucosa. ${ }^{92-94}$ Evidence that $H$ pylori eradication may reduce the risk of gastric cancer is based on non-randomised controlled studies in animal and humans. ${ }^{95} 96$ Several randomised control studies show regression of precancerous lesions or, at least, a decrease of progression as compared with control groups after $H$ pylori eradication. ${ }^{97}$ One RCT did not demonstrate reduction of cancer incidence at five years but showed a significant reduction in the group without pre-neoplastic lesions. ${ }^{98}$ The consensus report concluded that eradication of
$H$ pylori has the potential to reduce the risk of gastric cancer development; moreover, the optimal time to eradicate $H$ pylori is before pre-neoplastic lesions (atrophy, intestinal metaplasia) are present. It was also agreed, that the potential for gastric cancer prevention globally is restricted by currently available treatments. ${ }^{96-99}$ Thus, new treatments are desirable for a global strategy of gastric cancer prevention.

\section{ACKNOWLEDGEMENT}

The meeting was made possible by generous grants offered by Altana, AstraZeneca, Janssen Cilag, Takeda, and Malesci (main sponsor for the local event).

\section{Authors' affiliations \\ P Malfertheiner, Otto-von-Guericke University of Magdeburg, Magdeburg, Germany \\ F Megraud, INSERM U853, Bordeaux, France \\ C O'Morain, Adelaide and Meath Hospital, Trinity College, Dublin, Ireland \\ F Bazzoli, University of Bologna, Bologna, Italy \\ E El-Omar, Aberdeen University, Aberdeen, UK \\ D Graham, VA Medical Center Houston, Texas, USA \\ R Hunt, McMaster University, Hamilton, Ontario, Canada \\ T Rokkas, Henry-Dunant Hospital, Athens, Greece \\ N Vakil, University of Wisconsin Medical School, Milwaukee, USA \\ E J Kuipers, Erasmus MC University Medical Center, Rotterdam, \\ Netherlands}

\section{Competing interests: None}

Extracts in abstract form and comments have been published in Italian. Short extracts have been published in GI Forefront, based on a presentation to the Japanese Society of Gastroenterology and a European short version release.

Since the Maastricht conference new additional publications in support of the recommendations and statements, are included to update the manuscript.

\section{REFERENCES}

1 Malfertheiner P, Megraud F, O'Morain C, et al. Current concepts in the management of Helicobacter pylori infection - the Maastricht 2-2000 Consensus Report. Aliment Pharmacol Ther 2002;16:167-0.

2 Fischbach W, Dragosics B, Kolve-Goebeler ME, et al. Primary gastric B-cell lymphoma: results of a prospective multicenter study. The German-Austrian Gastrointestinal Lymphoma Study Group. Gastroenterology 2000;119:1191-202

3 Fischbach W, Goebeler-Kolve ME, Dragosics B, et al. Long term outcome of patients with gastric marginal zone B cell lymphoma of mucosa associated lymphoid tissue (MALT) following exclusive Helicobacter pylori eradication therapy: experience from a large prospective series. Gut 2004;53:34-7.

4 Chiba N, Van Zanten SJ, Sinclair P, et al. Treating Helicobacter pylori infection in primary care patients with uninvestigated dyspepsia: the Canadian adult dyspepsia empiric treatment-Helicobacter pylori positive (CADET-Hp) randomised controlled trial. BMJ 2002;324:1012-16.

5 Moayyedi P, Deeks J, Talley NJ, et al. An update of the Cochrane systematic review of Helicobacter pylori eradication therapy in nonulcer dyspepsia: resolving the discrepancy between systematic reviews. Am J Gastroenterol 2003;98:2621-6.

6 Moayyedi P, Soo S, Deeks J, et al. Systematic review and economic evaluation of Helicobacter pylori eradication treatment for non-ulcer dyspepsia. Dyspepsia Review Group. BMJ 2000;321:659-64.

7 Spiegel BM, Vakil NB, Ofman JJ. Dyspepsia management in primary care: a decision analysis of competing strategies. Gastroenterology 2002; 122:1270-85.

8 Metz DC, Kroser JA. Helicobacter pylori and gastroesophageal reflux disease. Gastroenterol Clin North Am. 1999;28: 971-85, viii).

9 Sharma P, Vakil N. Review article: Helicobacter pylori and reflux disease. Aliment Pharmacol Ther 2003;17:297-305.

10 Graham DY. The changing epidemiology of GERD: geography and Helicobacter pylori. Am J Gastroenterol 2003;98:1462-70.

11 Chow WH, Blaser MJ, Blot WJ, et al. An inverse relation between cagA+ve strains of $\mathrm{H}$. pylori infection and risk of esophageal and gastric cardia adenocarcinoma. Cancer Res 1998;58:588-90.

$12 \mathrm{Wu} \mathrm{AH}, \mathrm{Crabtree}$ JE, Bernstein L, et al. Role of H. pylori CagAt strains and risk of adenocarcinoma of the stomach and esophagus. Int $J$ Cancer 2003;103:815-21.

13 Ye W, Held M, Lagergren J, et al. H. pylori infection and gastric atrophy: risk of adenocarcinoma and squamous-cell carcinoma of the esophagus and adenocarcinoma of the gastric cardia, J Natl Cancer Inst 2004;96:388-96. 
$14 \mathrm{McColl} \mathrm{KE}$, Dickson A, El-Nujumi A, et al. Symptomatic benefit 1-3 years after $\mathrm{H}$. pylori eradication in ulcer patients:impact of gastroesophageal reflux disease. Am J Gastroenterol 2000;95:101-5.

15 Laine L, Sugg J. Effect of Helicobacter pylori eradication on development of erosive esophagitis and gastroesophageal reflux disease symptoms: a post hoc analysis of eight double blind prospective studies. Am J Gastroenterol 2002;97:2992-7.

16 Malfertheiner $\mathrm{P}$, Dent J, Zeiilon L, et al. Impact of $\mathrm{H}$. pylori eradication on heartburn in patients with gastric or duodenal ulcer disease - results from a randomized trial programme. Aliment Pharmacol Ther 2002;16:1431-42.

17 Moayyedi P, Bardhan C, Young L, et al. Helicobacter pylori eradication does not exacerbate reflux symptoms in gastroesophageal reflux disease. Gastroenterology 2001:121:1120-6.

18 Kuipers EJ, Nelis GF, Klinkenberg-Knol EC, et al. Cure of Helicobacter pylori infection in patients with reflux oesophagitis treated with long term omeprazole reverses gastritis without exacerbation of reflux disease: results of a randomised controlled trial. Gut 2004:53:12-20.

19 Schenk BE, Kuipers EJ, Nelis GF, et al. Effect of Helicobacter pylori eradication on chronic gastritis during omeprazole therapy. Gut 2000;46:615-21.

20 Huang JQ, Sridhar S, Hunt RH. Role of Helicobacter pylori infection and nonsteroidal anti-inflammatory drugs in peptic-ulcer disease: a meta-analysis. Lancet 2002;359:14-22.

21 Hawkey CJ, Tulassay Z, Szczepanski L, et al. Randomised controlled trial of Helicobacter pylori eradication in patients on non-steroidal anti-inflammatory drugs: HELP NSAIDs study. Helicobacter Eradication for Lesion Prevention. Lancet 1998:352:1016-21.

22 Chan FK, Chung SC, Suen BY, et al. Preventing recurrent upper gastrointestinal bleeding in patients with Helicobacter pylori infection who are taking low-dose aspirin or naproxen. N Engl J Med 2001;344:967-73.

23 Chan FK, To KF, Wu JC, et al. Eradication of Helicobacter pylori and risk of peptic ulcers in patients starting long-term treatment with non-steroidal antiinflammatory drugs: a randomised trial. Lancet 2002;359:9-13

24 Vergara M, Catalan M, Gisbert JP, et al. Meta-analysis: role of Helicobacter pylori eradication in the prevention of peptic ulcer in NSAID users. Aliment Pharmacol Ther 2005;21:1411-18.

25 Lai KC, Lam SK, Chu KM, et al. Lansoprazole for the prevention of recurrences of ulcer complications from long-term low-dose aspirin use. N Engl J Med 2002:346:2033-8.

26 DuBois S, Kearney DJ. Iron-deficiency anemia and Helicobacter pylori infection: a review of the evidence. Am J Gastroenterol 2005;100:453-9.

27 Annibale B, Marignani M, Monarca B, et al. Reversal of iron deficiency anemia after Helicobacter pylori eradication in patients with asymptomatic gastritis. Ann Intern Med 1999;131:668-72.

28 Ciacci C, Sabbatini F, Cavallaro R, et al. Helicobacter pylori impairs iron absorption in infected individuals. Dig Liver Dis 2004;36:455-60.

29 Gasbarrini A, Franceschi F, Tartaglione R, et al. Regression of autoimmune thrombocytopenia after eradication of Helicobacter pylori. Lancet 1998; $352: 878$

30 Franchini $M$, Veneri D. Helicobacter pylori infection and immune thrombocytopenic purpura: an update. Helicobacter 2004;9:342-6.

31 Fujimura K, Kuwana $M$, Kurata $Y$, et al. Is eradication therapy useful as the first line of treatment in $\mathrm{H}$. pylori-positive idiopathic thrombocytopenic purpura? Analysis of 207 eradicated chronic ITP cases in Japan. Int I Hematol 2005;81:162-8.

32 Franchini $M$, Veneri D. Helicobacter pylori-associated immune thrombocytopenia. Platelets 2006;17:712-17.

33 Tsutsumi $\mathrm{Y}$, Kanamori $\mathrm{H}$, Yamato $\mathrm{H}$, et al. Randomized study of $\mathrm{H}$. pylori eradication therapy and proton pump inhibitor monotherapy for idiopathic thrombocytopenic purpura. Ann Hematol 2005;84:807-11.

34 Bourke B, Ceponis P, Chiba N, et al. Canadian Helicobacter Study Group Consensus Conference: Update on the approach to Helicobacter pylori infection in children and adolescents - an evidence-based evaluation. Can J Gastroenterol 2005; 19:399-408.

35 Drumm B, Koletzko S, Oderda G. Helicobacter pylori infection in children: a consensus statement. European Paediatric Task Force on Helicobacter pylori. J Pediatr Gastroenterol Nutr 2000:30:207-13.

36 Gisbert JP, Pajares JM. Review article: C-urea breath test in the diagnosis of Helicobacter pylori infection-a critical review. Aliment Pharmacol Ther 2004;20:1001-17.

37 Gisbert JP, Pajares JM. Stool antigen test for the diagnosis of Helicobacter pylori infection: a systematic review. Helicobacter 2004;9:347-68.

38 Laheii RJ, Straatman H, Jansen JB, et al. Evaluation of commercially available Helicobacter pylori serology kits: a review. J Clin Microbiol 1998:36:2803-9.

39 Chey WD, Fendrick AM. Noninvasive Helicobacter pylori testing for the "testand-treat" strategy: a decision analysis to assess the effect of past infection on test choice. Archiv Intern Med 2001;161:2129-32.

40 Vakil N, Rhew D, Soll A, et al. The cost-effectiveness of diagnostic testing strategies for Helicobacter pylori. Am J Gastroenterol 2000:95:1691-8.

41 Gatta L, Vakil N, Ricci C, et al. Effect of proton pump inhibitors and antacid therapy on $13 \mathrm{C}$ urea breath tests and stool test for Helicobacter pylori infection. Am J Gastroenterol 2004;99:823-9.

42 Stoschus B, Dominguez-Munoz JE, Kalhori N, et al. Effect of omeprazole on Helicobacter pylori urease activity in vivo. Eur I Gastroenterol Hepatol 1996;8:811-13

43 Savarino V, Bisso G, Pivari M, et al. Effect of gastric acid suppression on 13Curea breath test: comparison of ranitidine with omeprazole. Aliment Pharmacol Ther 2000;14:291-7.
44 Bravo LE, Realpe JL, Campo C, et al. Effects of acid suppression and bismuth medications on the performance of diagnostic tests for Helicobacter pylori infection. Am J Gastroenterol 1999;94:2380-3.

45 Kokkola A, Rautelin H, Puolakkainen P, et al. Diagnosis of Helicobacter pylori infection in patients with atrophic gastritis: comparison of histology, 13C-urea breath test, and serology. Scand J Gastroenterol 2000;35:138-41.

46 Lehours $\mathbf{P}$, Ruskone-Fourmestraux $A$, Lavergne $A$, et al. Which test to use to detect Helicobacter pylori infection in patients with low-grade gastric mucosaassociated lymphoid tissue lymphoma? Am J Gastroenterol 2003:98:291-5.

47 Graham DY, Opekum AR, Hammoud F, et al. Studies regarding the mechanism of false negative urea breath test with proton pump inhibitors. Am J Gastroenterol 2003;98:1005-9.

48 Graham DY, Opekun AR, Yamaoka Y, et al. Early events in proton pump inhibitor-associated exacerbation of corpus gastritis. Aliment Pharmacol Ther 2003; 17:193-200

49 Ekstrom AM, Held M, Hansson LE, et al. Helicobacter pylori in gastric cancer established by CagA immunoblot as a marker of past infection. Gastroenterology $2001 ; 121: 784-91$

50 Loy CT, Irwig LM, Katelaris PH, et al. Do commercial serological kits for Helicobacter pylori infection differ in accuracy? A meta-analysis. Am J Gastroenterol 1996;91:1138-44.

51 Cover TL, Blaser MJ. Helicobacter pylori factors associated with disease. Gastroenterology 1999;117:257-61

52 El-Omar EM, Carrington M, Chow WH, et al. Interleukin-1 polymorphisms associated with increased risk of gastric cancer. Nature 2000;404:398-402.

53 Rogge JD, Wagner DR, Carrico RJ, et al. Evaluation of a new urease reagent strip for detection of Helicobacter pylori in gastric biopsy specimens. Am J Gastroenterol 1995;90:1965-8.

54 Vaira D, Holton J, Menegatti M, et al. Review article:invasive and non-invasive tests for Helicobacter pylori infection. Aliment Pharmacol Ther 2000;14(Suppl 3): 13-22.

55 Bilardi C, Biagini R, Dulbecco $P$, et al. Stool antigen assay (HpSA) is less reliable than urea breath test for post-treatment diagnosis of Helicobacter pylori infection. Aliment Pharmacol Ther 2002;16:1733-8.

56 Parente F, Maconi G, Porro GB, et al. Stool test with polyclonal antibodies for monitoring Helicobacter pylori eradication in adults: a critical reappraisal. Scand J Gastroenterol 2002;37:747-9.

57 Perri F, Manes G, Neri M, et al. Helicobacter pylori antigen stool test and 13Curea breath test in patients after eradication treatments. Am J Gastroenterol 2002;97:2756-62.

58 Gisbert JP, Pajares JM. Diagnosis of Helicobacter pylori infection by stool antigen determination: a systematic review. Am J Gastroenterol $2001 ; 96: 2829-38$

59 Makristathis A, Barousch W, Pasching E, et al. Two enzyme immunoassays and PCR for detection of Helicobacter pylori in stool specimens from pediatric patients before and after eradication therapy. J Clin Microbiol 2000;38:3710-14.

60 De Francesco V, Zullo A, Margiotta M, et al. Sequential treatment for Helicobacter pylori does not share the risk factors of triple therapy failure. Aliment Pharmacol Ther 2004;19:407-14.

61 Zullo A, Vaira D, Vakil N, et al. High eradication rates of Helicobacter pylori with a new sequential treatment. Aliment Pharmacol Ther 2003;17:719-26.

62 Glupczynski Y, Megraud F, Lopez-Brea M, et al. European multicentre survey of in vitro antimicrobial resistance in Helicobacter pylori. Eur J Clin Microbiol Infect Dis 2001;20:820-3.

63 Cars O, Molstad S, Melander A. Variation in antibiotic use in the European Union. Lancet 2001;357:1851-3.

64 Megraud F, Lamouliatte H. Review article: the treatment of refractory Helicobacter pylori infection. Aliment Pharmacol Ther 2003;17:1333-43.

65 Pilofto $A$, Leandro $G$, Franceschi $M$, et al. The effect of antibiotic resistance on the outcome of three 1-week triple therapies against Helicobacter pylori. Aliment Pharmacol Ther 1999;13:667-73.

66 McMahon BJ, Hennessy TW, Bensler JM, et al. The relationship among previous antimicrobial use, antimicrobial resistance, and treatment outcomes for Helicobacter pylori infections. Ann Intern Med 2003;139:463-9.

67 Malfertheiner P, Megraud F, O'Morain C, et al. Current European concepts in the management of Helicobacter pylori infection-the Maastricht Consensus Report. The European Helicobacter Pylori Study Group (EHPSG) Eur I Gastroenterol Hepatol 1997;9:1-2.

68 Fischbach LA, van Zanten S, Dickason J. Meta-analysis: the efficacy, adverse events, and adherence related to first-line anti-Helicobacter pylori quadruple therapies. Aliment Pharmacol Ther 2004;20:1071-82.

69 Megraud F. H. pylori antibiotic resistance: prevalence, importance, and advances in testing, Gut 2004;53:1374-84.

70 Megraud F. Update on therapeutic options for Helicobacter pylori-related diseases. Curr Infect Dis Rep 2005;7:115-20.

71 Ford A, Moayyedi P. How can the current strategies for Helicobacter pylori eradication therapy be improved? Can J Gastroenterol 2003;17/Suppl B):36-40B.

72 Calvet $\mathrm{X}$, Gene $\mathrm{E}$, Lopez $\mathrm{T}$, et al. What is the optimal length of proton pump inhibitor-based triple therapies for $\mathrm{H}$. pylori? A cost-effectiveness analysis. Aliment Pharmacol Ther 2001;15:1067-76.

73 Lamouliatte H, Megraud F, Delchier JC, et al. Second-line treatment for failure to eradicate Helicobacter pylori: a randomized trial comparing four treatment strategies. Aliment Pharmacol Ther 2003;18:791-7.

74 Realdi G, Dore MP, Piana A, et al. Pretreatment antibiotic resistance in Helicobacter pylori infection: results of three randomized controlled studies. Helicobacter 1999:4:106-12. 
75 Gisbert JP, Morena F. Systematic review and meta-analysis: levofloxacin-based rescue regimens after Helicobacter pylori treatment failure. Aliment Pharmacol Ther 2006;23:35-44.

76 Saad R, Schoenfeld P, Hyungiin MK, et al. Levofloxacin-based triple therapy versus bismuth-based quadruple therapy for persistent Helicobacter pylori infection: a meta-analysis. Am J Gastroenterol 2006;3:488-96.

77 Toracchio S, Cellini L, Di Campli E, et al. Role of antimicrobial susceptibility testing on efficacy of triple therapy in Helicobacter pylori eradication. Aliment Pharmacol Ther 2000; 14:1639-43.

78 Romano M, Marmo R, Cuomo A, et al. Pretreatment antimicrobial susceptibility testing is cost saving in the eradication of Helicobacter pylori. Clin Gastroenterol Hepatol 2003;1:273-8.

79 Brever T, Graham DY. Costs of diagnosis and treatment of Helicobacter pylori infection: when does choosing the treatment regimen based on susceptibility testing become cost effective? Am J Gastroenterol 1999;94:725-9.

80 Helicobacter and Cancer Collaborative Group. Gastric cancer and Helicobacter pylori: a combined analysis of 12 case control studies nested within prospective cohorts. Gut 2001:49:347-53.

81 Uemura N, Okamoto S, Yamamoto S, et al. Helicobacter pylori infection and the development of gastric cancer. N Engl J Med 2001;345:784-9.

82 Uemura N, Mukai T, Okamoto S, et al. Effect of Helicobacter pylori eradication on subsequent development of cancer after endoscopic resection of early gastric cancer. Cancer Epidemiol Biomarkers Prev 1997;6:639-42.

83 Signorello LB, Ye W, Fryzek JP, et al. Nationwide study of cancer risk among hip replacement patients in Sweden. J Natl Cancer Inst 2001;93:1405-10.

84 Huang JQ, Zheng GF, Sumanac K, et al. Meta-analysis of the relationship between cagA seropositivity and gastric cancer. Gastroenterology 2003; 125: 1636-44

85 Imsland AK, Eldon BJ, Arinbjarnarson S, et al. Genetic epidemiologic aspects of gastric cancer in Iceland. J Am Coll Surg. 2002;195: 181-6; discussion 6-7).

86 Moller H, Nissen A, Mosbech J. Use of cimetidine and other peptic ulcer drugs in Denmark 1977-1990 with analysis of the risk of gastric cancer among cimetidine users. Gut 1992;33:1166-9.

87 Brinton LA, Gridley G, Hrubec Z, et al. Cancer risk following pernicious anaemia. Br J Cancer 1989:59:810-13.

88 De Block CE, De Leeuw IH, Bogers JJ, et al. Autoimmune gastropathy in type 1 diabetic patients with parietal cell antibodies: histological and clinical findings. Diabetes Care 2003;26:82-8.

89 Aragones N, Pollan M, Gustavsson P. Stomach cancer and occupation in Sweden: 1971-89. Occup Environ Med 2002;59:329-37.

90 Palli D, Russo A, Ottini L, et al. Red meat, family history, and increased risk of gastric cancer with microsatellite instability. Cancer Res 2001;61:5415-19.

91 Malfertheiner P, Sipponen P, Naumann M, et al. H. pylori Gastric Cancer Task Force. H. pylori eradication has the potential to prevent gastric cancer: a state-ofthe-art critique, Am J Gastroenterol 2005;100:2100-15.

92 Kuipers EJ, Klinkenberg-Knol EC, Vandenbroucke-Grauls CM, et al. Role of Helicobacter pylori in the pathogenesis of atrophic gastritis. Scand J Gastroenterol 1997;223:28-34

93 Ohkuma K, Okada M, Murayama H, et al. Association of Helicobacter pylori infection with atrophic gastritis and intestinal metaplasia. J Gastroenterol Hepatol 2000;15:1105-12.

94 Asaka M, Sugiyama T, Nobuta A, et al. Atrophic gastritis and intestinal metaplasia in Japan: results of a large multicenter study. Helicobacter 2001;6:294-9.

95 Nozaki K, Shimizu N, Ikehara Y, et al. Effect of early eradication on Helicobacter pylori-related gastric carcinogenesis in Mongolian gerbils. Cancer Sci 2003;94:235-9.
96 Ley C, Mohar A, Guarner J, et al. Helicobacter pylori eradication and gastric preneoplastic conditions: a randomized, double-blind, placebo-controlled trial. Cancer Epidemiol Biomarkers Prev 2004;13:4-10.

97 Zhou L, Sung JJ, Lin S, et al. A five-year follow-up study on the pathological changes of gastric mucosa after $\mathrm{H}$. pylori eradication. Chinese Med J 2003:116:11-14

98 Wong BC, Lam SK, Wong WM, et al. Helicobacter pylori eradication to prevent gastric cancer in a high-risk region of China: a randomized controlled trial. JAMA 2004;291:187-94.

99 Correa P, Fontham ET, Bravo JC, et al. Chemoprevention of gastric dysplasia: randomized trial of antioxidant supplements and anti-Helicobacter pylori therapy. J Natl Cancer Inst 2000;92:1881-8.

\section{APPENDIX \\ CONFERENCE PARTICIPANTS}

Andersen, Leif, Copenhagen, Denmark; Atherton, John, Nottingham, UK; Asaka, Masahiro, Sapporo, Japan; Bazzoli, Franco, Bologna, Italy; Bytzer, Peter, Glostrup, Denmark; Chan, Francio, Shatin, HongKong; Coelho, Luiz Gonzaga Vaz, Belo Horizonte, Brazil; de Wit, Niek, Utrecht, The Netherlands; Delchier, Jean Charles, Paris, France; Di Mario, Francesco, Padova, Italy; El-Omar, Emad, Aberdeen, UK; Fock, Kwong Ming, Singapore; Forman, David, Leeds, UK; Fujioka, Toshio, Oita, Japan; Gasbarrini, Giovanni, Roma, Italy; Genta, Robert, Geneva, Switzerland; Goh, KL, Kuala Lumpur, Malaysia; Graham, David Y, Houston, Texas, USA; Hirschl, Alexander, Wien, Austria; Hungin, Pali, Durham, UK; Hunt, Richard, Ontario, Canada; Isakov, Vassili A, Moscow, Russia; Jones, Roger, London, UK; Kist, Manfred, Freiburg, Germany; Koletzko, Sibylle, München, Germany; Kuipers, Ernst J, Amsterdam, The Netherlands; Kupcinskas, Limas, Kaunas, Lithuania; Ladas, Spiros, Athens, Greece; Lanas, Angel, Zaragoza, Spain; Machado, Jose, Porto, Portugal; Malfertheiner, Peter, Magdeburg, Germany; McColl, Kenneth E. L., Glasgow, Scotland, UK; Mégraud, Francio, Bordeaux, France; Michetti, Pierre, Lausanne, Schwitzerland; Moayyedi, Paul, Hamilton, Canada; OMorain, Colm, Dublin, Ireland; Pilotto, Alberto, Vicenza, Italy; Quina, Mario, Lisboa, Portugal; Rokkas, Theodore, Athens, Greece; Sharma, Patreek, Missouri, USA; Simsek, Ylkay, Izmir, Turkey; Sipponen, Pentii, Esposo, Finland; Sollano, J., Manila, Philippines; Stockbrügger, Reinold, Maastricht, The Netherlands; Sugano, Kentaro, Yakushiji Tochigi, Japan; Vaira, Dino, Bologna, Italy; Vakil, Nimish, Milwaukee, WI, USA; Vieth, Michael, Bayreuth, Germany; Xiao, Shudong, Shanghai, China.

\section{EDITOR'S QUIZ: GI SNAPSHOT}

\begin{abstract}
Answer
From the question on page 755

The CT scan showed a $3.4 \times 2.3 \mathrm{~cm}$ paracolic mass near to the left kidney without associated lymphadenopathy. The tumour was hypodense with an enhanced wall of the lesion (fig 1).

The histological examination of the CT-guided biopsy of the lesion demonstrated numerous Aspergillus fumigatus hyphae $(\mathrm{H} \& \mathrm{E} \times 400$; fig 2 ), which could be cultured on Sabourauds's medium.

Most Aspergillus infections are found in immunosuppressed patients and, typically, involve the lungs. This case documents a highly unusual extrapulmonary aspergilloma without secondary focus. The management is surgical. Our patient had a smooth postoperative course and was symptom free at a follow-up 5 years after the resection of the aspergilloma.
\end{abstract}

